\title{
A Study on the Change of Maternal Love in the Change of Childbirth and Child Care Environment
}

\section{출산 및 양육환경 변화에 따른 모성애 의식 변화 연구}

Seon-Nyeo $\mathrm{Kim}^{1}$

김선녀1

${ }^{l}$ Assistant Professor, Department of Social Welfare, Honam University, Korea, snkim@honam.ac.kr

\begin{abstract}
The purpose of this study is to explore the effects of childbirth and parenting environments on motherhood and social gender equality. To confirm this, a study was conducted on 852 women with at least three children living in six regions across the country (Seoul, Gyeonggi, Chungcheong, Gyeongsang, Jeolla, and Gangwon). As a result of this study, we found that the childbirth and parenting environment has a significant impact on motherhood and social gender equality. Eventually, it was found that the creation of a favorable childbirth and parenting environment affected maternal and social gender equality consciousness. It also allowed women to actively engage in childcare and social activities. The results of this study will be available for the establishment of maternity and childcare policies.
\end{abstract}

Keywords: Motherhood, Childbirth, Upbringing, Gender Equality, Policy

요약: 본 연구는 출산양육환경과 모성애 의식 변화의 연관성을 탐색하는 데 그 목적이 있으 며, 이를 확인하기 위해 전국 6개 지역(서울, 경기, 충청, 경상, 전라, 강원)에 거주하는 자녀 3 명 이상을 둔 여성 852명을 대상으로 연구를 진행하였다. 본 연구의 결과 출산양육환경이 모 성애 및 사회적 성평등 인식에 상당한 영향을 미친다는 점을 알 수 있었다. 결국 호의적인 출 산양육환경 조성이 모성애 변화에 영향을 미치게 되고, 이를 통해 여성이 육아와 사회 활동에 적극적으로 나설 수 있게 될 것임을 알 수 있었다. 본 연구 결과는 선순환 출산 및 육아 정책 수립에 활용될 수 있을 것이다.

핵심어: 모성애, 출산, 양육, 성평등, 정책

\section{1. 서론}

\section{1 연구의 필요성}

우리 사회는 출산한 여성이 모성애를 갖는다는 관념에 기반하여 여성에게 가사노동 및 양육을 포함하여 사회 활동까지 수행하여야 하는 '희생적인 어머니상'을 강요한 것이 아 닌지 우려스럽다. 뉴시스[1]에 따르면 2019년 아동학대로 사망한 아동은 42명인데, 가해자

Received: March 10, 2021; $1^{\text {st }}$ Review Result: April 26, 2021; $2^{\text {nd }}$ Review Result: June 14, 2021 Accepted: July 31, 2021 
대부분은 부모이며, 그 중 상당수가 친모임을 알 수 있다. 이러한 현상을 고려할 때 여성 들이 출산, 육아, 가사노동, 사회 활동 등에 대해 지나친 스트레스를 받고 있는 것은 아 닌지 우려스럽다.

여성에게만 아이를 보호하고 양육할 책임이 있다는 관념은 잘못된 것이며[2][3], 성평등 적 관점에서 모성애를 평가하려는 연구들이 진행되고 있기도 하지만, 경험적이고 실증적 인 자료를 근거로 설명하기에는 미흡한 부분이 있다.

본 연구에서는 출산 및 육아 환경이 모성애 변화에 영향을 미치는 중요 요인이라고 가 정하고, 이를 확인하고자 하였다.

\section{2. 이론적 고찰}

\section{1 사회 및 경제 변화와 모성애}

일찍이 서구의 역사에서는 '본성적으로 헌신적인 어머니’라는 이론을 활용하여 여성의 책임을 더 크게 확장시키기도 하였고[4], 필요에 따라 이를 축소하기도 하였다[5]. 그 대표적인 예가 2차 세계대전 이후 전쟁터에서 살아 돌아온 남성들의 노동 현장 복귀를 위해, 여성은 이제 '가정으로 돌아가라'라는 것이었다. 이는 자본가의 입맛에 따라 언제나 해고가 용이한 노동의 유연성을 노동시장에 정착시킴으로써 성적 불평등을 심화시키는 결과를 초래했다.

1970년대부터 남녀의 역할은 생물학적 요인이 아니라 사회화의 결과라고 보는 견해가 주류를 이루면서 파슨스(Talcott Parsons)의 전통적인 역할이론은 남녀사이의 불평등을 조장한다는 비판을 받았다[6]. 이러한 변화 흐름 속에서 성장발전주의를 표방해 온 정부 는 철저한 시장주의 체제를 추구하는 신자유주의의 경제 논리를 빠르게 흡수하면서 수면 아래 웅크리고 있던 여성의 진화된 모성애 가치관을 수면 위로 떠오르게 하는 데 일조했 다. 즉 한국사회의 사회·경제적 변화는 여성에게 있어서 성별분업의 변화, 모성애의 변화 그리고 새로운 모성 주체의 구성을 의미한다[7].

\section{2 출산 및 양육 환경과 모성애}

최근 부모의 아동학대, 영유아 살인이 사회문제로 이슈화 되고 있는데[8], 이는 출산여 성들이 자녀 양육 과정에서 마냥 행복하지만은 않을 것이라는 합리적 의심을 낳게 한다.

정윤주는 양육스트레스가 어머니 자신의 심리적 안녕 및 양육행동은 물론 자녀의 발달 에도 직·간접적으로 좋지 않은 영향을 끼친다고 강조하였다[9]. 돌봄노동 중에서 특히 양 육은 어머니인 여성이 수행해야 한다는 모성 이데올로기에 의해 지탱되어 왔으며, 여성 들 스스로도 이러한 모성 이데올로기를 내면화하고 실천해왔다[10].

천선영은 자녀를 부양할 수 있는 이상적인 조건을 제공할 수 없다면, 비출산이 더 책 임감있는 선택이라고 강조하고, 계획된 모성을 이성적 모성으로 정의하고 이성적 모성의 발현을 '어머니되기'의 새로움으로 해석함으로써 변화된 모성애를 재정의 하였다[11].

이러한 가운데 행정자치부의 '대한민국출산지도' 제작사건은 국가에 의해 가임기 여성 의 재생산 능력이 도구화되고 있다는 비판을 피하기 어려웠다. 특히「모자보건법」의 가 장 핵심적인 문제 중에 하나는 여성의 몸과 재생산 능력을 국가의 인구정책을 위해 통제 할 수 있는 대상으로 여기고 있다는 점이다.「모자보건법」에서 피임시술과 난임시술에 대한 조항은 인구정책에 따라 변화해왔는데, 임신을 하지 않기 위한 의료적 서비스와 임 
신을 하기 위한 의료적 서비스가 개인 여성의 필요와 욕구에 따라 지원되는 것이 아니라, 국가의 인구정책 기조에 따라서 변화해 온 것이다.

\section{3 사회적 양성 평등}

출산관련 정책연구에서 노동시장 정책, 돌봄 정책과 더불어 사회적 양성 평등 조성이 잘 연계된 국가에서 출산율이 더 잘 유지되고 있는 경향이 있음을 지적하고 있다. 또한 성 평등 수준이 높은 사회 혹은 가족 내 남녀 간 가사 분담이 공평하게 이루어지는 사회 일수록, 일정한 출산력 수준을 유지하고 있다고 밝힌다.

그러나 여성인력의 사회진출이 증가하고 여성들의 교육수준이나 전문성의 측면에서 남 성 못지않은 경력을 보임에도 불구하고 조직의 관리자로서 여성이 적합하지 않다는 인식 은 남성들의 남존여비 문화적 편향 및 성역할에 대한 고정관념의 결과라고 할 수 있다. 나아가 조직의 장이나 고위직 구성원 등 조직 구성원들의 높은 성 편견은 조직 내 승진 차별 구조를 정착시키는 등 여성들에게 불리한 조직 환경이나 문화를 유발함으로써 여성 의 정치·행정부문 진출에 부정적인 영향을 미치는 주요 변수가 된다.

또한, 한국의 출산정책의 효과성 연구에서 사회적 양성 평등을 포함하여 모두 21 개의 출산영향 요인에 대한 인식도와 경험이 향후 자녀의 출산계획에 영향이 미치는 것으로 분석하였다. 이를 종합하여 보면 사회적 양성 평등 즉 여성 권한 지수가 높다는 것은 사 회적 인식과 문화 및 정책부분에서 효과성 및 노동조건의 질적 향상으로 이어져 출산율 에 긍정적으로 작용하는 것으로 알려져 있다.

평등한 기회를 요구하는 가족친화 정책에 대한 페미니스트의 강조는 성차별이 노동시 장 결과에서의 성 차이의 주요 원천이며, 특히 여성과 남성과의 임금격차라는 것을 가정 한다.

\section{3. 연구 방법}

\section{1 연구 대상}

본 연구는 전국 6 개 지역(서울, 경기, 충청, 경상, 전라, 강원)에 거주하면서 자녀 3 명 이상을 둔 여성을 대상으로 2018년 7월 23일부터 9월 20일까지 진행하였으며, 총 870부 의 설문 중 유효한 850 부를 연구자료로 활용하였다.

\section{2 연구 도구}

김선녀의 박사학위 논문에 포함된 설문을 응용하여 연구 도구를 작성하였다. 연구에 사용된 변수들의 개념타당도를 알아보기 위해 설정된 항목들이 적합한가를 분석하는 $\mathrm{KMO}$ (Kaiser-Mayer-Olkin) 값이 .785로 나타나 요인분석에 사용된 변수들의 선정이 양호하 다고 진단할 수 있다.

또한 연구에 사용된 변수들이 특정 개념을 동일하게 설명하고 있는가를 검토하기 위해 신뢰도검정을 실시한 결과 Cronbach's $a$ 값이 .721 .813으로 나타나 본 연구에 사용된 변 수들은 항목 간 내적 일관성이 있음을 알 수 있다. 


\section{3 자료처리}

본 논문의 통계 분석을 위하여 SPSS WINDOW 21.0을 사용하여 통계처리를 진행하였다. 표본의 인구통계학적 분포 분석에는 빈도 분석(Frequency Analysis), 개념타당도 분석을 위 해 요인 분석, 개념신뢰도검정을 위해 크론바하 알파테스트 (Cronbach alpha test)를 통해 분석하였다. 연구개념의 평균과 표준편차 분석에는 기술통계(Descriptive analysis), 연구개념 들의 상관관계 및 영향관계 분석을 위해서는 상관관계분석(Correlation analysis)과 다중회귀 분석(Multiple regression Analysis)을 사용하였다. 매개효과분석은 Baron \& Kenny(1986)의 3단 계 매개효과 분석방법을 이용하여 분석하였다. 수집된 자료의 통계적인 유의수준을 검정 하기 위하여 유의 수준은 $a=.05$ 로 하였다.

\section{4. 연구 결과}

\section{1 연구개념 기술통계}

변화된 모성애가 $4.30 \pm 0.41$ 점, 출산양육환경이 $3.28 \pm 0.64$ 점, 사회적 성평등이 $4.17 \pm$ 0.52 점으로 나타났다. 조사대상자들의 연구개념 관련 평균 수준을 살펴 보면, 변화된 모 성애가 가장 높고, 사회적 성평등이 두 번 째로 높으며, 출산양육환경이 가장 낮은 것으 로 나타났다.

[표 1] 연구개념 기술통계

[Table 1] Research Concept Technical Statistics

\begin{tabular}{c|c|c|c|c|c}
\hline \hline & $\mathrm{N}$ & 최소값 & 최대값 & 평균 & 표준편차 \\
\hline 변화된 모성애 & 847 & 2.89 & 5.00 & 4.30 & 0.41 \\
\hline 출산양육환경 & 850 & 1.00 & 5.00 & 3.28 & 0.64 \\
\hline 사회적 성평등 & 849 & 2.43 & 5.00 & 4.17 & 0.52 \\
\hline
\end{tabular}

\section{2 연구개념들 사이의 상관관계}

변화된 모성애와 출산양육환경 사이에는 $(\mathrm{r}=0.256)$, 변화된 모성애와 사회적 성평등 사 이에는 $(\mathrm{r}=0.362)$ 로 상관크기가 나타나 $5 \%$ 유의수준 이상에서 통계적으로 유의한 중간 정 도의 상관관계가 있다고 해석할 수 있다.

출산양육환경과 사회적 성평등 사이에는 $(\mathrm{r}=0.130)$ 로 상관크기가 나타나 $5 \%$ 유의수준 이상에서 통계적으로 유의한 약한 상관관계가 있다고 해석할 수 있다. 
[표 2] 연구개념 상관분석

[Table 2] Research Concept Correlation Analysis

\begin{tabular}{c|c|c|c}
\hline \hline & 변화된 모성애 & 출산양육환경 & 사회적 성평등 \\
\hline 변화된 모성애 & 1 & 1 & \\
\hline 출산양육환경 & $.256(* *)$ & $.130(* *)$ & 1 \\
\hline 사회적 성평등 & $.362(* *)$ & .30 & 1 \\
\hline
\end{tabular}

\section{3 연구가설 검증 결과}

출산양육환경와 모성애 변화, 사회적 양성 평등의 관계를 분석하기 위해 Baron과 Kenny(1986)가 제안한 3단계 매개회귀분석을 통하여 가설 검증을 실시하였다.

[표 3] 출산양육환경와 모성애 변화의 관계

[Table 3] Relationship between Childbirth and Child Care Environment and Maternal Change

\begin{tabular}{|c|c|c|c|c|c|c|c|}
\hline & \multicolumn{2}{|c|}{ 비표준화 계수 } & \multirow{2}{*}{$\begin{array}{c}\begin{array}{c}\text { 표준화 } \\
\text { 계수 }\end{array} \\
\text { 베타 }\end{array}$} & \multirow{2}{*}{$\mathrm{t}$} & \multirow{2}{*}{ 유의확률 } & \multicolumn{2}{|c|}{ 공선성 통계량 } \\
\hline & $\mathrm{B}$ & 표준오차 & & & & 공차한계 & VIF \\
\hline (상수) & 1.491 & 0.223 & & 6.700 & 0.000 & & \\
\hline 1. 변화된 모성애 & 0.152 & 0.029 & 0.181 & 5.199 & $0.000^{* * *}$ & 0.779 & 1.284 \\
\hline 2. 양육책임 의식 & 0.023 & 0.022 & 0.037 & 1.035 & 0.301 & 0.722 & 1.384 \\
\hline 3. 전통적 모성애 & 0.018 & 0.018 & 0.033 & 0.965 & 0.335 & 0.823 & 1.215 \\
\hline 4. 자녀를 우선 & 0.086 & 0.022 & 0.139 & 3.890 & $0.000^{* * *}$ & 0.734 & 1.363 \\
\hline 5. 가치관 충돌 & -0.023 & 0.021 & -0.036 & -1.077 & 0.282 & 0.833 & 1.200 \\
\hline 6. 사회인식 변화 & 0.092 & 0.028 & 0.115 & 3.300 & $0.001 * *$ & 0.769 & 1.300 \\
\hline 7. 엄마(자신)의 행복 & 0.031 & 0.038 & 0.029 & 0.821 & 0.412 & 0.773 & 1.293 \\
\hline 8 자녀와의 상호작용 & 0.035 & 0.030 & 0.044 & 1.136 & 0.256 & 0.625 & 1.599 \\
\hline 9. 엄마(자신)의 존재 & 0.013 & 0.037 & 0.015 & 0.355 & 0.722 & 0.558 & 1.791 \\
\hline
\end{tabular}




\begin{tabular}{c|c|c|c|c|c|c|c}
\hline 1. 양가부모의 관심 & 0.086 & 0.021 & 0.152 & 4.202 & $\mathbf{0 . 0 0 0 * * *}$ & 0.719 & 1.391 \\
\hline 2. 양가부모의 도움 & 0.027 & 0.019 & 0.051 & 1.449 & 0.148 & 0.749 & 1.336 \\
\hline 3. 지역사회 환경 & 0.022 & 0.017 & 0.041 & 1.248 & 0.212 & 0.861 & 1.161 \\
\hline 4. 지역사회 정보 & 0.056 & 0.024 & 0.095 & 2.370 & $\mathbf{0 . 0 1 8 *}$ & 0.582 & 1.718 \\
\hline 5. 지역사회 네트워크 & -0.025 & 0.023 & -0.044 & -1.052 & 0.293 & 0.538 & 1.859 \\
\hline 6. 지역사회의 신뢰 & 0.008 & 0.016 & 0.019 & 0.519 & 0.604 & 0.711 & 1.407 \\
\hline 7. 이웃과의 소통 & 0.027 & 0.020 & 0.051 & 1.341 & 0.180 & 0.655 & 1.526 \\
\hline 8. 놀이공간 관심도 & -0.026 & 0.020 & -0.048 & -1.264 & 0.207 & 0.664 & 1.506 \\
\hline 9. 출산 출하 정서문화 & 0.029 & 0.024 & 0.044 & 1.203 & 0.229 & 0.697 & 1.435 \\
\hline
\end{tabular}

$R 2=0.225, F=13.279, p=0.000 * * *$

* 종속변수: 사회적 성평등

*** $\mathrm{p}<0.001, * * \mathrm{p}<0.01, * \mathrm{p}<0.05$

변화된 모성애가 사회적 성평등에 미치는 영향에 대한 출산양육환경의 매개효과를 분 석하기 위해 다중회귀분석을 실시한 결과 회귀식은 $(\mathrm{R} 2=0.143, \mathrm{~F}=70.284, \mathrm{p}<.001)$ 로 $5 \%$ 유 의수준 이상에서 통계적으로 유의한 영향관계가 있는 것으로 나타났다. 독립변수별로 보 면 변화된 모성애 $(\beta=0.356, \mathrm{p}<.001)$, 출산양육환경 $(\beta=0.110, \mathrm{p}<.01)$ 이 $5 \%$ 유의수준 이상에서 통계적으로 유의한 영향을 미치고 있다. 출산양육환경 매개변수는 부분매개효과를 가지 는 것으로 나타났다.

[표 4] 출산양육환경, 변화된 모성애가 사회적 성평등에 미치는 영향-다중회귀분석

[Table 4] The Influence of Childbirth and Parenting Environment and Changed Maternal Love on Social Gender Equality-Multiple Regression Analysis

\begin{tabular}{|c|c|c|c|c|c|c|c|}
\hline & \multicolumn{2}{|c|}{ 비표준화 계수 } & \multirow{2}{*}{$\begin{array}{c}\text { 표준화 계수 } \\
\text { 베타 }\end{array}$} & \multirow{2}{*}{$\mathrm{t}$} & \multirow{2}{*}{ 유의확률 } & \multicolumn{2}{|c|}{ 공선성 통계량 } \\
\hline & B & 표준오차 & & & & 공차한계 & VIF \\
\hline (상수) & 1.921 & 0.191 & & 10.036 & 0.000 & & \\
\hline 변화된 모성애 & 0.454 & 0.041 & 0.356 & 11.146 & $0.000 * * *$ & 0.997 & 1.003 \\
\hline 출산양육환경 & 0.089 & 0.026 & 0.110 & 3.436 & $0.001 * *$ & 0.997 & 1.003 \\
\hline
\end{tabular}

$\mathrm{R} 2=0.143, \mathrm{~F}=\mathbf{7 0 . 2 8 4}, \mathrm{p}=\mathbf{0 . 0 0 0} * * *$ 


\section{5. 결론}

본 연구는 3 명 이상의 자녀를 둔 다자녀 여성을 대상으로 출산양육환경의 변화가 모성 애 변화에 미치는 영향, 그리고 사회적 성평등 인식에 미치는 영향을 탐색하고자 진행되 었다. 주요 연구결과를 바탕으로 논의할 수 있는 내용은 다음과 같다.

첫째, 자녀의 출산 및 양육이 여성들만의 전유물이 아니라 가족, 지역공동체가 함께 책 임져야 한다는 의식이 고조됨으로써, 출산 및 양육을 여성이 온전히 책임져야 한다는 의 식에도 변화가 있었으며, 이로 인해 전통적인 모성애 의식이 변화하고 있음을 알 수 있 었다.

둘째, 자녀의 출산 및 양육에 대한 의식 변화가 사회적 양성 평등 의식에 미치는 영향 을 분석한 결과, 양가부모의 관심과 실질적인 도움, 지역사회 환경과 정보, 출산 축하 정 서 문화의 변화로 인해 남성뿐 아니라 주변인들도 출산과 육아에 책임이 있다는 의식이 확대되면서, 결론적으로 양성 평등 의식 확산에도 영향을 미친 것으로 볼 수 있었다. 다 만, 지역사회 네트워크와 신뢰, 이웃과의 소통 부분은 아직 미흡하다고 분석되었다.

셋째, 모성애 인식 변화가 사회적 양성 평등에 미치는 영향에 대한 출산양육환경의 매 개효과를 분석한 결과 영향관계가 있는 것으로 나타났으며, 하위요인 중 양가부모의 관 심, 지역사회 정보에서 유의한 부분매개효과를 가지고 있는 것으로 나타났다. 즉, 여성의 변화된 모성애 인식이 직접적으로 사회적 양성 평등 인식에 영향을 주었을 뿐만 아니라 출산양육환경을 매개로 유의미한 영향을 주기도 하였다. 이는 출산양육환경이 사회적으 로 인식하는 성 평등에 영향을 미쳐 다자녀출산의지에 긍정적으로 작용한다는 것을 실증 적으로 보여주는 것이며, 다자녀출산에 있어 가족과 지역사회의 실질적 지지가 중요한 요소임을 말해준다.

넷째, 인구학적 변인은 서울에 거주할수록, 배우자의 직업형태가 정규직일수록, 소득이 높을수록, 변화된 모성애 인식과 출산양육환경 수준이 높을수록 사회적 성평등 인식이 높은 것으로 분석되었다. 이러한 결과가 의미하는 것은 여성이 출산을 의도하기 위해서 는 배우자의 직업과 소득이 안정적으로 유지되어야 하며, 가사노동과 양육과정에서도 성 평등한 역할 분담이 이루어져야 하고, 사회적으로 인식하는 성평등의 수준도 높아져야 함을 시사한다. 반면 여성 본인의 직업형태와의 관계는 유의하지 않은 것으로 보아 여전 히 배우자의 소득에 의존하는 경향이 크며, 비정규직, 임시직 등 현재 노동시장에서 벌어 지는 여성의 불안정한 직업형태를 그대로 반영하고 있다.

이상의 연구 결과를 토대로 출산 및 육아 정책에 대한 제언을 하면 다음과 같다.

첫째, 자녀의 출산과 양육에 있어, 여성이 오로지 희생적인 어머니로서 존재하는 것이 아니라, 여자로서, 사회인으로서, 이기적인 한 인간으로서 살고 싶은 권리를 함께 인정할 수 있는 환경을 조성할 필요가 있을 것이다.

둘째, '한 아이를 키우기 위해서는 온 마을이 필요하다.'는 말처럼, 출산과 양육을 여성 에게만 책임지도록 하지 않고, 가족 및 지역사회, 국가공동체가 함께 책임질 수 있는 정 책을 개발할 필요가 있을 것이다.

본 연구는 3자녀 이상을 둔 여성만을 대상으로 실시하였기 때문에 연구결과를 일반화 하여 해석하기에는 무리가 있을 수 있으므로, 추후 연구에서는 연구대상을 확대할 필요 가 있다. 


\section{References}

[1] https://www.newsis.com/view/?id=NISX20210219_0001344621, Newsis, Feb 19 (2021)

[2] Orna Donath, Regretting Motherhood: A Study, North Atlantic Books, California, USA, (2017)

[3] Eun Young Choi, A Qualitative Research on the Project and Fragmentation of Motherhood in Korean Women, Seoul National University, Ph.D. Thesis, (2014)

[4] Elisabeth Badinter, Mother Love, Macmillan Pub Co., USA, (1982)

[5] Jin Ok Lee, Invention of 'motherhood' in eighteenth century England, The Korean Journal of British Studies, (2018), Vol.40, pp.71-109, https://kiss.kstudy.com/thesis/thesis-view.asp?key=3652457

[6] Hai-Sook Kim, So Yeon Yoon, The Characteristics and the Effectiveness of Female Leaders: The Effect of the Organizational Culture of Gender Prejudice, Korean Journal of Social and Personality Psychology, (2009), Vol.23, No.1, pp.33-54, DOI: 10.21193/kjspp.2009.23.1.003

[7] G. Rosemary, Contextualizing voluntary childlessness within a postmodern model of reproduction : implications for health and social needs, Critical Social Policy, (2001), Vol.21, No.2, pp.139-159, DOI: https://doi.org/10.1177/026101830102100201

[8] In-choon Kim, Jung-won Choi, Low Fertility Trend and Gender Equality in S. Korea: For the Complementarities of Population Policy and Women's Policy, Social Science Studies, (2008), Vol.16, No.1, pp.312-343, DOI: 10.17787/jsgiss.2008.16.1.312

[9] https://news.zum.com/articles/67169165, Segye Ilgo, Mar 25 (2021)

[10] Yunju Jung, Yunjoo Kim, The Effects of NLP Counseling Program on Parenting Stress, Psychological Well-being, and Parenting Attitude among Mothers: The Case of Those with Preschooler or School-aged Children, Korean Journal of Health Psychology, (2007), Vol.19, No.2, pp.485-512, DOI: 10.17315/kjhp.2014.19.2.003

[11] Seon-Young Cheon, The Newness of Mothering: Between Desire and Anxiety, Korean Journal of Social Theory, (2002), Vol.22, No.12, pp.285-332, https://academic.naver.com/article.naver?doc_id=36891943 